\title{
Temperature Sensitive Spinel-Type Ceramics in Thick-Film Multilayer Performance for Environment Sensors
}

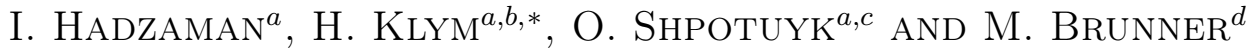 \\ ${ }^{a}$ Lviv Institute of Materials of Scientific Research Company "Carat", Stryjska 202, 79031 Lviv, Ukraine \\ ${ }^{b}$ Lviv Polytechnic National University, Bandera 12, 79013 Lviv, Ukraine \\ ${ }^{c}$ Institute of Physics of Jan Długosz University of Czestochowa \\ al. Armii Krajowej 13/15, 42-201 Częstochowa, Poland \\ ${ }^{d}$ Fachhochschule Köln/University of Applied Sciences, Betzdorfer 2, 50679 Köln, Germany

\begin{abstract}
Temperature sensitive thick films based on spinel-type semiconducting ceramics of different chemical composition $\mathrm{Cu}_{0.1} \mathrm{Ni}_{0.1} \mathrm{Co}_{1.6} \mathrm{Mn}_{1.2} \mathrm{O}_{4}$ (with $p^{+}$-types of electrical conductivity), $\mathrm{Cu}_{0.1} \mathrm{Ni}_{0.8} \mathrm{Co}_{0.2} \mathrm{Mn}_{1.9} \mathrm{O}_{4}$ (with p-types of electrical conductivity) and their multilayer $p^{+}-p$ structures were fabricated and studied. These thick-film elements possess good electrophysical characteristics before and after long-term ageing test at $170{ }^{\circ} \mathrm{C}$. It is shown that degradation processes connected with diffusion of metallic Ag into film grain boundaries occur in one-layer $p$ - and $p^{+}$-conductive thick films. The $p^{+}-p$ structures were of high stability, the relative electrical drift was not greater than $1 \%$.
\end{abstract}

PACS numbers: 81.05.Je, 07.07.Df

\section{Introduction}

The use of spinel-based $\mathrm{NiMn}_{2} \mathrm{O}_{4}-\mathrm{CuMn}_{2} \mathrm{O}_{4}-$ $\mathrm{MnCo}_{2} \mathrm{O}_{4}$ manganites with negative temperature coefficient (NTC) resistance for fabrication of disc-type NTC thermistors by means of conventional ceramic technology was shown by us earlier [1-2]. However, applications in modern microelectronics (temperature and heating sensors, fire detectors, power-sensing terminations, temperature-compensating attenuators, etc. [3-6]) require obtaining these thermistor materials in thick-film performance.

The well-known advantages of screen printing technology revealed in high reproducibility, flexibility, attainment of high reliability by glass coating as well as excellent accuracy, yield and interchangeability by functional trimming are expected to be very attractive now, for new-generation sensing electronics [6]. No less important is the factor of miniaturization for developed thick-film elements and systems, realized in a variety of their possible geometrical configurations. Thus, the development of high-reliable nanostructured thick films and their multilayers based on spinel-type compounds for environment sensors operating as simultaneous NTC thermistors and integrated temperature-humidity sensors are very important task [7-9].

Thick-film performance of mixed spinel-type manganites restricted by $\mathrm{NiMn}_{2} \mathrm{O}_{4}-\mathrm{CuMn}_{2} \mathrm{O}_{4}-\mathrm{MnCo}_{2} \mathrm{O}_{4}$

* corresponding author; e-mail: klymha@yahoo.com concentration triangle has a number of essential advantages, non-available for other ceramic composites. Within the above system, there can be prepared the fine-grained semiconductor materials possessing $p^{+}$. -conductive $\mathrm{Cu}_{0.1} \mathrm{Ni}_{0.1} \mathrm{Co}_{1.6} \mathrm{Mn}_{1.2} \mathrm{O}_{4}$ and $p$-conductive $\mathrm{Cu}_{0.1} \mathrm{Ni}_{0.8} \mathrm{Co}_{0.2} \mathrm{Mn}_{1.9} \mathrm{O}_{4}$. So, a real possibility to prepare multilayer thick-film spinel-type structures for principally new device application, such as thermoelectric transformers in a power supply, high-accurate temperature sensors and compensators exploring current-voltage dependence, temperature difference detecting elements utilizing thermoelectromotive force, etc., seems to be a quite realistic one. In addition, the prepared multilayer thick-film structures involving semiconductor $\mathrm{NiMn}_{2} \mathrm{O}_{4}-$ $\mathrm{CuMn}_{2} \mathrm{O}_{4}-\mathrm{MnCo}_{2} \mathrm{O}_{4}$ and dielectric $\mathrm{MgAl}_{2} \mathrm{O}_{4}$ spinels can be potentially used as simultaneous thermistors and integrated temperature-humidity sensors with a wide range of exploitation properties.

The aim of this work is a development and studies of high-reliable temperature sensitive thick films and multilayered structures based on spinel-type ceramics for future multifunctional application in integrated temperature/humidity sensors.

\section{Experimental}

Bulk ceramics were prepared by a conventional ceramic processing route using reagent grade copper carbonate hydroxide and nickel (cobalt, manganese) carbonate hydroxide hydrates [10]. Chemical composition of these ceramics and the main points in their sintering schedules are presented in Table I. 
TABLE I

Chemical composition, temperature and duration of isothermal sintering for the investigated ceramics.

\begin{tabular}{c|c}
\hline \hline Chemical composition & $\begin{array}{c}\text { Sintering } \\
\text { temperature/duration }\end{array}$ \\
\hline $\mathrm{Cu}_{0.1} \mathrm{Ni}_{0.1} \mathrm{Co}_{1.6} \mathrm{Mn}_{1.2} \mathrm{O}_{4}$ & $1040^{\circ} \mathrm{C} / 4 \mathrm{~h}$ \\
\hline $\mathrm{Cu}_{0.1} \mathrm{Ni}_{0.8} \mathrm{Co}_{0.2} \mathrm{Mn}_{1.9} \mathrm{O}_{4}$ & $\begin{array}{r}92{ }^{\circ} \mathrm{C} / 8 \mathrm{~h}+1200^{\circ} \mathrm{C} / 1 \mathrm{~h} \\
+920^{\circ} \mathrm{C} / 24 \mathrm{~h}\end{array}$
\end{tabular}

Temperature sensitive $\mathrm{Cu}_{0.1} \mathrm{Ni}_{0.1} \mathrm{Co}_{1.6} \mathrm{Mn}_{1.2} \mathrm{O}_{4} /$ $\mathrm{Cu}_{0.1} \mathrm{Ni}_{0.8} \mathrm{Co}_{0.2} \mathrm{Mn}_{1.9} \mathrm{O}_{4}$-based pastes were prepared by mixing powders of basic ceramics (sintered bulk ceramic discs were preliminary crushed, wet-milled in isopropyl alcohol medium and dried) with ecological glass powder, $\mathrm{Bi}_{2} \mathrm{O}_{3}$ (inorganic binder) and an organic vehicle (contained organic binder and organic solvent). Thus, the two thermistor pastes on the basis of the spinel-type ceramics were obtained (Table II).

\section{TABLE II}

Composition of the temperature sensitive pastes.

\begin{tabular}{c|c}
\hline \hline Constituents & Content [\% mass] \\
\hline basic ceramics & 72.8 \\
$\mathrm{Bi}_{2} \mathrm{O}_{3}$ & 2.9 \\
ecological glass & 2.9 \\
organic vehicle & 21.4
\end{tabular}

The prepared pastes were printed on alumina substrates (Rubalit 708S) with prefired $\mathrm{Ag}-\mathrm{Pt}$ electrodes using a manual screen-printing device equipped with a steel screen. Then, thick films were fired in PEO-601-084 furnace. To increase the thickness of layer (to obtain the $p^{+}-p$ structures) the double printing procedure was used. Thick films were fired at $850^{\circ} \mathrm{C}$ (the temperature-time firing schedule was similar to that applied for the metallization of disk-type thermistors).

In the case under consideration, the main advantages proper to bulk transition-metal manganite ceramics (wide range of electrical resistance with a high temperature sensitivity) were transformed into thick-film multilayer resulting in a principally new and more wider functionality. The spinel-type $\mathrm{Cu}_{0.1} \mathrm{Ni}_{0.1} \mathrm{Co}_{1.6} \mathrm{Mn}_{1.2} \mathrm{O}_{4}$ compounds with $p^{+}$-type of electrical conductivity and $\mathrm{Cu}_{0.1} \mathrm{Ni}_{0.8} \mathrm{Co}_{0.2} \mathrm{Mn}_{1.9} \mathrm{O}_{4}$ compound with $p$-type of electrical conductivity were designed as overall integrated $p^{+}-p$ structures shown in the topological scheme (Fig. 1).

The phase composition and the crystal structure of phases of fired thick films were determined by X-ray diffraction (XRD) powder method. XRD patterns were recorded from the surfaces of thick films at room temperature using a powder DRON-2.0M diffractometer with $\mathrm{Fe} K_{\alpha}$ radiation. The measurements were carried out in

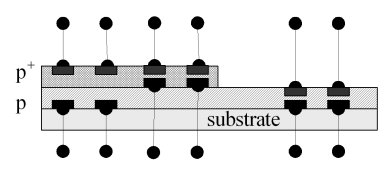

Fig. 1. Topological scheme of temperature sensitive thick-film structures.

a step regime $\left(0.025^{\circ}, 10 \leq 2 \theta \leq 140\right)$. The profile analysis was performed using the method of approximation of X-ray reflections by pseudo-Voigt function. The lattice parameters and the crystal structure of the phases were refined using the Rietveld method with the program FULLPROF.2k [11] from the WinPLOTR software [12].

The topology of the obtained thick films was investigated using Rodenstock RM600 3D-profilograph. The electrical resistances of temperature-sensitive thick films were measured with precise digital multimeters using MINI SABZERO temperature chambers, model MC-71 and HPS 222. The temperature constant $B$ for these thick films was calculated according to the equation

$$
B=2.3026 \log \left(\frac{R_{1}}{R_{2}}\right) \frac{T_{1} T_{2}}{T_{2}-T_{1}},
$$

where $R_{1}$ and $R_{2}$ were, accordingly, resistances at $T_{1}=$ $25^{\circ} \mathrm{C}$ and $T_{2}=85^{\circ} \mathrm{C}$.

The long-term ageing test at $170^{\circ} \mathrm{C}$ for $p$-, $p^{+}$-type thick films and their $p^{+}-p$ structures was carried out for the study of their reliability. The current-voltage $I-V$ characteristics were measured at $25^{\circ} \mathrm{C}$ and $5{ }^{\circ} \mathrm{C}\left( \pm 0.1^{\circ} \mathrm{C}\right)$ using a precise digital multimeter. The relative change of electrical resistance $\left(\Delta R / R_{0}\right)$ was used as a controlled parameter $\left(R_{0}\right.$ - initial value of the electric resistance, $\Delta R$ - absolute change of the electric resistance caused by an ageing test).

\section{Results and discussion}

According to obtained 3D-profilograph data, the thickness of temperature sensitive $p^{+}$-conductive thick films based on $\mathrm{Cu}_{0.1} \mathrm{Ni}_{0.1} \mathrm{Co}_{1.6} \mathrm{Mn}_{1.2} \mathrm{O}_{4}$ ceramics and $p$ -conductive thick films based on $\mathrm{Cu}_{0.1} \mathrm{Ni}_{0.8} \mathrm{Co}_{0.2} \mathrm{Mn}_{1.9} \mathrm{O}_{4}$ ceramics were near $47-49 \mu \mathrm{m}$ and $54-63 \mu \mathrm{m}$, respectively. The topology of multilayered $p^{+}-p$ thick-film structures is shown in Fig. 2.

XRD measurements for the thick film based on $p^{+}$-conductive $\mathrm{Cu}_{0.1} \mathrm{Ni}_{0.1} \mathrm{Co}_{1.6} \mathrm{Mn}_{1.2} \mathrm{O}_{4}$ ceramics show, that it contains one crystalline phase: cubic spinel $\left(\mathrm{MgAl}_{2} \mathrm{O}_{4}{ }^{-}\right.$ -type structure, space group $F d \overline{3} m, a=8.30130(9) \mathrm{nm}$, $V=0.572057(11) \mathrm{nm}^{3}$ (see Fig. 3a). The residuals are as follows: $R_{\mathrm{Bragg}}=0.0450, R_{\mathrm{F}}=0.0375, \chi^{2}=7.60$, $R_{\mathrm{p}}=0.0452, R_{\mathrm{wp}}=0.0566$. The thick film based on $p$-conductive $\mathrm{Cu}_{0.1} \mathrm{Ni}_{0.8} \mathrm{Co}_{0.2} \mathrm{Mn}_{1.9} \mathrm{O}_{4}$ ceramics contains two crystalline phases: cubic spinel with $a=$ 8.3794(1) nm, $V=0.58835(1) \mathrm{nm}^{3}\left(R_{\text {Bragg }}=0.0498\right.$, $\left.R_{\mathrm{F}}=0.0396, \chi^{2}=3.61, R_{\mathrm{p}}=0.0360, R_{\mathrm{wp}}=0.0456\right)$, and traces of NiO-based secondary phase with NaCl-type structure (space group $F m \overline{3} m$ ) (Fig. 3b). Previously, the 


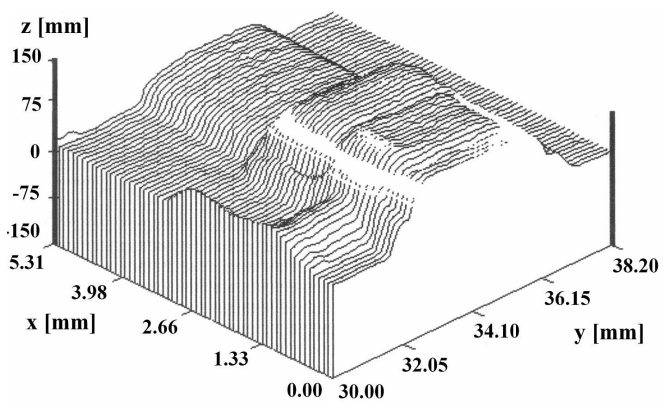

Fig. 2. Topology of $p^{+}-p$ thick-film structures obtained by Rodenstock RM600 3D-profilograph.

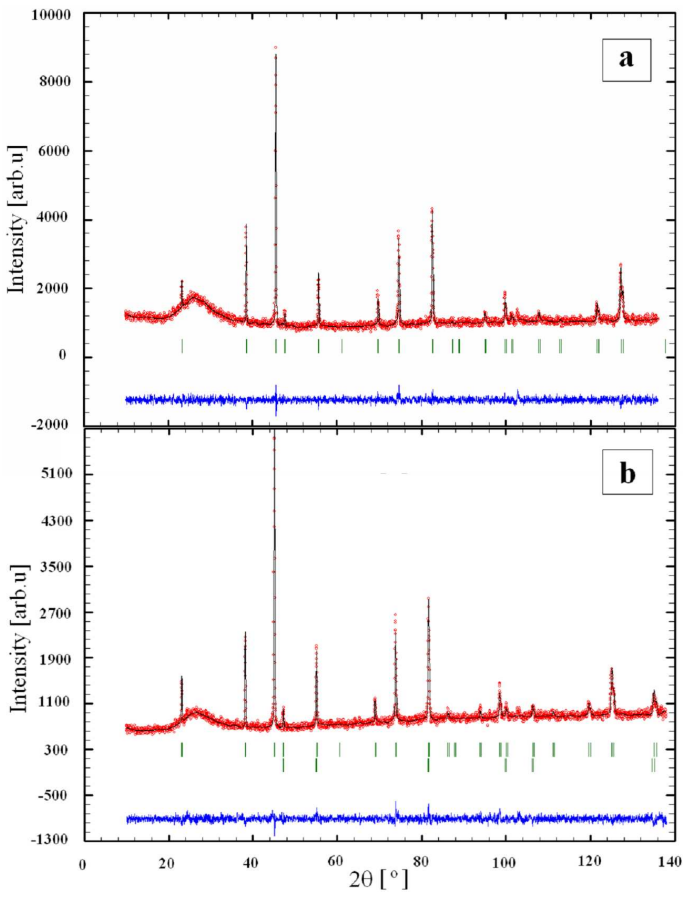

Fig. 3. Observed and calculated XRD profiles for $p^{+}$-conductive $\mathrm{Cu}_{0.1} \mathrm{Ni}_{0.1} \mathrm{Co}_{1.6} \mathrm{Mn}_{1.2} \mathrm{O}_{4}$ (a) and $p$ -conductive $\mathrm{Cu}_{0.1} \mathrm{Ni}_{0.8} \mathrm{Co}_{0.2} \mathrm{Mn}_{1.9} \mathrm{O}_{4}$ (b) thick films (the overhead row of reflexes is the spinel phase, the lower row of reflexes is $\mathrm{NiO}$ phase).

formation of such NiO-based secondary phase traces was observed in $\mathrm{Cu}_{0.1} \mathrm{Ni}_{0.8} \mathrm{Co}_{0.2} \mathrm{Mn}_{1.9} \mathrm{O}_{4}$ ceramics sintered for $1 \mathrm{~h}$ at $1200^{\circ} \mathrm{C}$ due to decomposition reactions $[13,14]$. We expected that the reverse reactions in ceramics will proceed during the following long-term sintering for $24 \mathrm{~h}$ at $920^{\circ} \mathrm{C}$ and a single-phase cubic spinel will be obtained. But, as one can see, the traces of secondary phase are present after fulfillment of sintering procedure. So, the duration of this additional thermal treatment was insufficient, i.e., the sintering of $\mathrm{Cu}_{0.1} \mathrm{Ni}_{0.8} \mathrm{Co}_{0.2} \mathrm{Mn}_{1.9} \mathrm{O}_{4}$ ceramics was not perfect for a single-phase material synthesis. However, XRD studies for $p^{+}$-conductive thick film based on $\mathrm{Cu}_{0.1} \mathrm{Ni}_{0.1} \mathrm{Mn}_{1.2} \mathrm{Co}_{1.6} \mathrm{O}_{4}$ ceramics show only the spinel phase, pattern of alumina substrate and do not re- veal any traces of NiO-phase. It means, that the reverse reactions came to the end during the thermal treatment of films firing.

The temperature sensitive $p^{+} / p$-conductive thick films and their $p^{+}-p$ structures based on spinel-type $\mathrm{NiMn}_{2} \mathrm{O}_{4}{ }^{-}$ $\mathrm{CuMn}_{2} \mathrm{O}_{4}-\mathrm{MnCo}_{2} \mathrm{O}_{4}$ ceramics possess good linear electrophysical characteristics in the region from $298 \mathrm{~K}$ to $358 \mathrm{~K}$ in semi-logarithmic scale (Fig. 4). The values of $B$ constants were $3589 \mathrm{~K}, 3630 \mathrm{~K}$ and $3615 \mathrm{~K}$ for $p$-, $p^{+}$conductive thick films and $p^{+}-p$ structure, respectively.

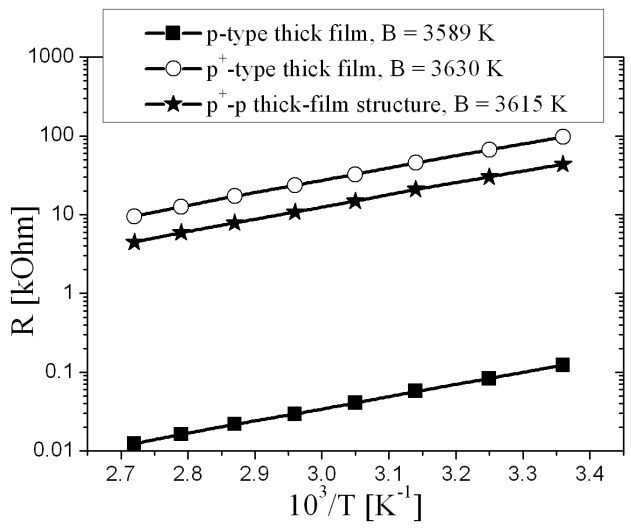

Fig. 4. $R(T)$ characteristics for temperature-sensitive $p$ - and $p^{+}$-conductivity thick films and for $p^{+}-p$ thick-film structure.

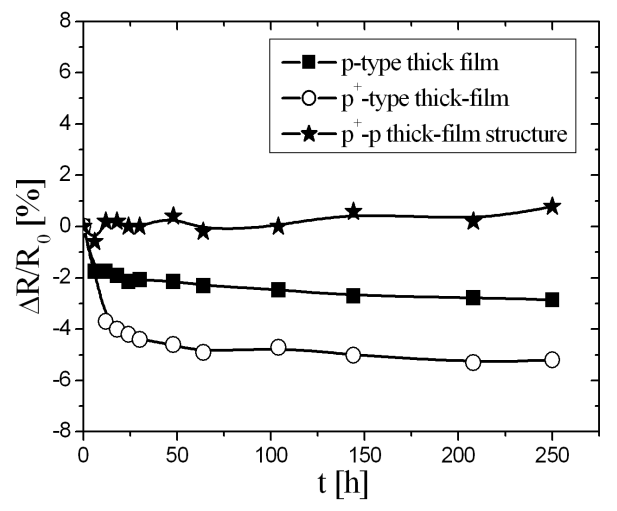

Fig. 5. Thermally-induced $\left(170{ }^{\circ} \mathrm{C}\right)$ relative resistance drift $\left(\Delta R / R_{0}\right)$ in thick-film elements.

It is shown that the electrical resistance of $p$ - and $p^{+}-$ conductive thick films incidentally decreases in the process of degradation test (see Fig. 5). This effect is supposed to be connected with thermally-induced compression of thick films and diffusion of metallic $\mathrm{Ag}$ into the grain boundaries. The value of $\Delta R / R_{0}$ reaches $-(2-5) \%$. However, the $p^{+}-p$ thick-film structure shows high reliability after long-term ageing test at $170^{\circ} \mathrm{C}$. The relative electrical drift is no more than $1 \%$.

The values of the temperature constant $B$ are decreased in $20-50 \mathrm{~K}$ after degradation test for both $p / p^{+}$-conductive thick films and their $p^{+}-p$ structures, while 
the activation energy of the electrical conductivity was not changed significantly, being at the level of $0.31 \mathrm{eV}$. Typical current-voltage characteristics for $p$-conductive thick films are presented in Fig. 6.

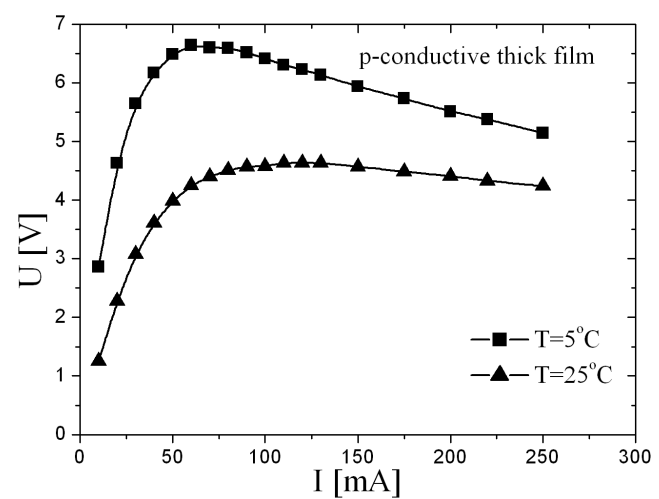

Fig. 6. $I-V$ characteristics for $p$-conductive thick films.

In our previous work [15] there was shown that the dielectric (d-type) humidity-sensitive thick film based on $\mathrm{MgAl}_{2} \mathrm{O}_{4}$ ceramics possess good linear dependence of the electrical resistance from relative humidity without hysteresis in the range of $\mathrm{RH} \approx 40-99 \%$, and it can be used for humidity sensors. Since all components $\left(p-, p^{+}-\right.$and d-type thick films) are of the same chemical type (spinel-like) and possess high temperature/humidity sensitivities, they will be positively distinguished not only by a wider functionality (simultaneous temperature-humidity sensing), but also unique functional reliability and stability. To prepare such multifunctional temperature/humidity sensitive elements, we will use typical design performance in respect the scheme shown in Fig. 1, where the humidity-sensitive $d$-type layer is placed between $p^{+}$and $p$-type layers $\left(p^{+}-\mathrm{d}-p\right.$ structure). Within proposed configuration, several simultaneous functions will be available via resistance measurements between different points of this multifunctional element: $p / p^{+}$-type thick-film elements will be used as in-rush current limiter and temperature sensors utilizing current-voltage dependence of thick-film in $p^{+}-p$ junctions will be used as temperature sensor utilizing thick-film capacitor $p^{+}-\mathrm{d}-p$ with water-sensitive dielectric layer $d$.

So, the next work will be concerned with the studies of integrated temperature/humidity sensitive $p^{+}-\mathrm{d}-p$ structures for multifunctional environment sensors.

\section{Summary}

The temperature sensitive thick-film elements based on spinel-type $\mathrm{NiMn}_{2} \mathrm{O}_{4}-\mathrm{CuMn}_{2} \mathrm{O}_{4}-\mathrm{MnCo}_{2} \mathrm{O}_{4}$ manganites with $p^{+} / p$-type of electrical conductivity and their $p^{+}-p$ structures were prepared using ecological glass con- stituents. These thick-film elements possess good electrophysical characteristics before and after long-term ageing test at $170^{\circ} \mathrm{C}$. The degradation processes connected with diffusion of metallic Ag into the film grain boundaries occur in one-layer $p$ - and $p^{+}$-conductive thick films. The $p^{+}-p$ structures were of high stability, the relative electrical drift was no more than $1 \%$. Thus, these thick films can be used to produce multifunctional high-reliable integrated temperature and humidity sensors for effective environment monitoring and control.

\section{Acknowledgments}

The authors acknowledge the research support from Science and Technology Center in Ukraine under regular STCU Project No. 4277 and the helpful assistance of Dr. P. Demchenko from Ivan Franko National University of Lviv for obtaining and interpretation of XRD data of the investigated thick films.

\section{References}

[1] M. Vakiv, O. Shpotyuk, O. Mrooz, I. Hadzaman, J. Europ. Ceram. Soc. 21, 1783 (2001).

[2] M.M. Vakiv, I.V. Hadzaman, A.P. Kovalskiy, M.M. Kravtsiv, O.Ya. Mrooz, O.I. Shpotyuk, Patent of Ukraine No. 47534, $\mathrm{H} 01 \mathrm{C} 7 / 04, \mathrm{H} 01 \mathrm{C} 7 / 13$, C04B35/00 // C04B101:00, Prior.: 06.04.2000.

[3] V.I. Zaharov, A.O. Olesk, Elektronnaja Tehnika, Ser. Radiodetali i Komponenty 65, 30 (1989).

[4] V.I. Zaharov, A.O. Olesk, Zarubeznaja Elektronnaja Tehnika 5, 43 (1983).

[5] J. Zhong, H.H. Bau, Am. Ceram. Soc. Bull. 80, 39 (2001).

[6] A.H. Feingold, R.L. Wahlers, P. Amstutz, C. Huang, S.J. Stein, J. Mazzochette, Microwave J. 1, 90 (2000).

[7] W. Qu, Meas. Sci. Technol. 11, 1111 (2000).

[8] N.W. White, J.D. Turner, Meas. Sci. Technol. 8, 1 (1997).

[9] A. Dziedzic, Meas. Sci. Technol. 8, 78 (1997).

[10] I. Vynnyk, I. Hadzaman, H. Klym, O. Mrooz, O. Shpotyuk, Technology and Design in Electronics 2, 60 (2006).

[11] J. Rodriguez-Carvajal, in: Abstr. Satellite Meeting on Powder Diffraction of the XV Congress of the IUCr, Toulouse, France 1990, p. 127.

[12] T. Roisnel, J. Rodriguez-Carvajal, in: Materials Science Forum, Proc. Seventh European Powder Diffraction Conference (EPDIC 7), Barcelona, 2000, p. 118.

[13] O. Mrooz, I. Hadzaman, M. Vakiv, O. Shpotyuk, J. Plewa, H. Altenburg, H. Uphoff, in: Proc. 23rd Int. Conf. Microelectronics (MIEL 2002), Yugoslavia, Vol. 1, 2002, p. 375 .

[14] O. Bodak, L. Akselrud, P. Demchenko, B. Kotur, O. Mrooz, J. Alloys Comp. 374, 12 (2002).

[15] H. Klym, I. Hadzaman, O. Shpotyuk, M. Brunner, in: Proc. 14th Int. Conf. on Sensors, Technologies, Electronics and Applications, Germany, Vol. 2, 2009, p. 74 . 